region. Whether that was salpingitis or appendicitis he is, of course, unable to say, as he did not see the patient until six months after the onset of the neuritis. Dr. Swan, with whoin Dr. Sinkler saw the patient, did not see her at the time of the onset of the trouble, as she was not from Philadelphia, but from many hundred miles away.

\section{A CLINICAL STUDY OF HEMIPLEGIA IN THE} ADULT.*

THEODORE H. WEISENBURG, M.D.

Instructor in Nervous Diseases and in Neuropathology, University of Pennsylvania: Assistant Neurologist to the rhiladelphia General Hospital. PHILADELPHIA.

(From the Philadelphia General Hospital.)

There is no organic nervous disease more common than hemiplegia or a disease of which there has been more witten, and yet the study of hemiplegia is always interesting and profitable. Advantage was taken of the excellent opportunities offered by the nervous wards of the Philadelphia General Hospital to make a study of hemiplegia. A number of cases were alio studied in the nervous services of the University and the Polyclinic hospitals.

In all 160 cases were observed. Particular attention was paid to the following subjects: Heredity, prehemiplegic and posthemiplegic pain, atrophy of the muscles of the paralyzed and of the sound side, respiration, the various trophic phenomena, as edema and the arthropathics, rasomotor disturbances and hemichorca.

Of the 160 clinical cases, only 109 werc considered in the study of heredity, prehemiplegic and posthemiplegic pain and sensation, because of the unreliability of some of the statements or the aphasic conditions. All of the cases were in the adult.

A greater portion were in the male sex, but the conditions werc such that it was hardly fair to draw conclusions regarding the frequency of the disease in the sexes. It is, however, well recognized that hemiplegia occurs more often in the male than in the female. Of the 160 cases, $9 \%$ were right-sided. This proportion is, perhaps, not so great as one would expect, for most writers insist on the preponderance of right-sided hemiplegia.

\section{HEREDITY.}

Hereditary predisposition for hemiplegia in certain families has been observed, and it probably depends on a tendency to inherit a diseased condition of the blood vessels. Fourteen of the 109 cases gave such a history. In five the mother had hemiplegia, in five others the father, in one case both of the parents died of a stroke, in another the grandfather and the father had hemiplegia, while in two cases the grandmother and the mother each died of apoplexy.

Dr. Wm. G. Spiller has very kindly furnished me the details of a most interesting history of a patient who recently had a slight hemiplegia. Eight brothers and sisters of the patient's mother tied of apoplexy, but his mother did not. The mother of the patient's mother also died of apoplexy. The patient hiniself has had two children, both of whom are living and well. This is a very extraordinary family history and show $z$ how strongly the hereditary tendency may be. I have been unable to obtain the details of a similar instance in the literature.

* Read in the Section on Nervous and Mental Diseases of the American Medical Association, at the Fifty-fifth Annual Session, June, 1904.
In the listories obtained of most of these patients a number of other children in the families were said to be healtlyy. It is necessary, therefore, to have an active contributory cause. It can be assumed that in the first ten cases the occurrence of hemiplegia in either the father or the mother was accidental, but in the last five instances the hereditary tendency was strongly manifest, especially in the last instance. There was neither a special tendency for the paralysis to involve the same side in the parent and the child, nor involve the same sex.

\section{PREILEMIPLEGIC PAIN.}

Weir Mitchell, ${ }^{1}$ in 1893 , called attention to the occurrence of prehemiplegic pain. He then recorded three such cases. In one the pain appeared two years before the onset of the hemiplegia and was violent in character. This patient had three strokes, all of which were preceded by pain. In another case the pains were accompanied by a painful swelling of the joints. Subsequently there was a cerebral hemorrhage and a resulting hemiplegia on the same side as the pains. The joint lesions persisted. Férre, ${ }^{2}$ in a study of 126 cases of hemiplegia, found that 14 had prehemiplegic pain.

Seventeen cases of the 109 had pains of varying character before the onset of the hemiplegia. Of these in seven instances the pain was described as a violent. shooting, cutting pain, in two as a dull, aching feeling, and in five as a tingling, tired, numb, or a pinsand-needle sensation. In all these cases the pains occurred on the side of the subsequent paralysis, in one instance, as in Weir Mitchell's case, two years before, in another one year before, and in others six, three and two months respectively before the onset of the hemiplegia. Except in the above cases the pains were mostly felt for from twenty-four to forty-eight. hours before or just before the onset of the paralysis. One patient complained of sharp, persistent headache for six months, another of a feeling like an electric shock just before his stroke.

The pains were manifested mostly in the muscular tissues and the articulations of the upper extremity, and less often of the lower extremity. Sometimes they were present in the chest and side of the face. In one instance the pain was present for six months only in the distribution of the sciatic nerve. Férré records three similar cases. In another case of an intelligent physi cian they were localized to the distribution of the median nerve for two days. Dr. A. S. Hamilton, of the Independence State Hospital of Iowa, has kindly furnished me with the record of a most interesting case of a man who was "aroused by something he knows not what, and almost immediately afterward it seemed to him as if an explosion had occurred very close at hand. He heard a terrific noise and saw a bright flash and at the same time felt as if he had been struck a very heavy blow in the side of the head. This was the beginning of an apoplectic seizure. About two hours after his stroke he became conscious, and since has persistently given the above facts."

In five of these cases the pains ceased after the onset of the hemiplegia. The pains occurring with hemiplegia are undoubtedly of cortical origin and several theories have been advanced to explain them. It has been thorrht that the congestion of the cerebral vessels which $i$ supposed to precede the attack may be the

1. Welr Mitchell: Medical News, p. 421, 1893

2. Férré and Brissaud: Quoted by Marle, P.. Hémiplegle, in Traité de Médecine et de Therapeutique, vol. vill, Paris, 1901. 
cause. It is not to be denied that there may be cerebral congestion previous to an apopleptic attack, but it has seemed to me from the study of these cases that the socalled premonitory symptoms, as headache, fullness of the head, roaring in the ears and dizziness, are, on the whole, not so common as described. Most of the attacks come on without the slightest premonitory symptoms, either while the patient is at rest, or, as in a large number of cases, during sleep.

Brissaud has explained these pains by an involvement of the meninges. This may be a satisfactory explanation for those cases in which the pains occur for some time before the onset of the hemiplegia, for in all of my cases in which the pains occurred for some time before the attack, in five, the pains persisted with equal severity after the attack began. In five of the milder instances, those in which the pains occurred one or two days before, they ceased after the attack began. In these cases and for the other similar ones in which the pain persisted it may be that cerebral congestion, or rather an actual small hemorrhage in the region of the sensory pathway, would explain the condition. No satisfactory explanation can be given, however, for the occurrence of pains limited to one nerve, as the sciatic, unless this was an accidental complication, probably a neuritis.

Still another explanation may be given. It is possible that in a hemiplegia due to a thrombosis a gradually diminishing blood supply to a part of the cortex would cause nutritional disturbance, which would account for the pain. In the cases under consideration, however, this did not seem to be the explanation.

\section{POSTHEMIPLEGIC PAIN.}

Hemiplegia can be said to be a painful disease. It is rare, indeed, for a person suffering from this affection not to complain of some form of ache or pain. In the 109 clinical cases studied, twenty-seven had distinct pain of a sharp, shooting character, twelve of different forms of paresthesia, and the other seventy patients complained of soreness in the muscles and joints of the paralyzed side, and in only five of the series was there no pain or ache complained of.

A subdivision may be made of these pains according to their character. In the largest class belong those persons in whom there is an uneasiness or feeling of soreness in the various joints and muscles of the paralyzed side, especially of the shoulder joint. This is not so apparent in the hemiplegics where there are little or no contractures, or where the spasticity is not marked, but in the patients in whom these conditions are prominent there is always some pain on movement. Then, again, there is the pain which is due to the weight of the arm dragging on an ankylosed joint.

A second subdivision may be made for those cases in which the patients complain of the different forms of paresthesia, as a feeling of tingling or numbness, a "growing" or a dull feeling, or an itching sensation. These may be present either in the whole affected side or only in the distal parts of the extremities. Twelve of my cases showed these phenomena. In the marked instances there was always an accompanying hypesthesia of the affected side either for touch and pain or for both. There are several explanations for these rymptoms. Lessened blood supply and a conseque, at nutritional disturbance, and at times acciden ind injuries causing a neuritis, as by dragging of a limb, are very often the cause, but they are doubtless sometimes due to a cortical or subcortical lesion, especially in the cases where there are accompanying sensory changes.

In the third subdivision may be placed the pains of the more severe type. These are variously described as sharp, shooting, cutting, aching, twisting and so forth. Of the 109 cases, twenty-seven had more or less severe pain. These were mostly present in the upper extremity, and were more marked in the cases where ankylosis was extreme. They did not bear a special relation to the degree of atrophy present, as Brissaud and lately Marie have held.

I did not make any special study of the state of the sensation in the paralyzed side, but the following conditions were noted: There were two cases of total hemianesthesia for all forms of sensation and twentyeight cases of hypesthesia for either touch or pain or both. Of these thirty cases, eight had little or no pain, five complained of paresthetic phenomena and seventeen of various pains. It may be said, therefore, that pain in hemiplegia is more liable to occur where there are sensory changes.

The pains were present mostly from the shoulder to the wrist, and from the hip to the knee and sometimes to the ankle. Again, they were at times manifested in the side of the chest. In most of these instances movement did not increase the pain. Diminished vascular supply, spasticity and sometimes an accompanying neuritis explains many of these conditions, but in a number of my cases the pains were undoubtedly due to a central origin.

It is my intention to take up the subject of central pain in a subsequent paper where posthemiplegic central pain will be more fully discussed.

\section{RESPIRATION.}

Hughlings Jackson, ${ }^{3}$ in 1891 , called attention to the fact that in the respiratory movements of hemiplegics the superior intercostal muscles of the paralyzed side have a greater amplitude in quiet or automatic respiration, but that in forced or extraordinary respiration the movements on the sound side are always greater. Since that time these observations have been confirmed, and lately by Clarke ${ }^{4}$ and Bury. ${ }^{5}$ Gowers, however, does not think that there is any difference in the respiratory movements, and Boeri ${ }^{7}$ believes that in most instances the respiratory movements are held back not only in quiet, but also in forced respiration.

In nearly every case of the 160 examined I was able to confirm Jackson's observation that in quiet or ordinary respiration the upper part of the chest of the paralyzed side expands more than does the corresponding part of the sound side, but that in forced respiration the movements on the sound side are always greater. The movements vary in different patients, sometimes the difference being hardly perceptible. The observation is made while the patient is either standing or sitting.

I have, however, observed that at the end of ordinary or quiet expiration ine chest on the sound side has a longer range of movement, that is, that it retracts more than does thie chest on the paralyzed side. If the patient is asked to lie down, this phenomenon is shown even mrie distinctly. Dr. Spiller was good enough to confirm this observation. This being so, it means that the amount of air expelled from the lung on the sound

3. Jackson, Iughlings: The Lancet, Jan, 14, 1893.

4. Clark, I. P.: Am. Jour. Med. Scien., December, 1903.

5. Bury: The Lancet, Dec. 19. 1903.

6. Gowers: Ibis. of Nervons System, pp. 75. 89, vol. 11

7. Hoert: Gaz. Hebd. de Med., Na. 7, p. 73. 
side is greater, that there is more remaining residual air at the end of expiration in the lung of the paralyzed side, and that the movement of the lung is actually weaker on the affected side.

If the lungs are percussed at the end of expiration, the note obtained on the paralyzed side is always deeper.

'The amount of air breathed in during the inspiratory act is probably the same in either lung, but the Iung on the hemiplegic side has to accommodate the same amount of air as the healthy lung, plus the increased quantity of residual air, hence the increased superior intercostal excursion. In forced respiration the diminished respiratory movements of the lung of the paralyzed side are easily seen. We must come to the conclusion, therefore, that both in quiet and in forced respiration the respiratory movements are diminished on the paralyzed side of the body.

'The usual explanation offered has been the loss of the cortical inhibitory control over the medullary respiratory centers, and, as a result of this withdrawal of inhibition, the medullary center overacts in ordinary or automatic respiration.

It is well known that movements, not muscles, are represented in the cortex, and it may be expected, therefore, that in a lesion, such as would result in a hemiplegia, there would be total loss of function on the opposite side. That this is not so in muscles, which habitually act together, as in the elevation of the brow, in respiratory and laryngeal movements, is well known. Broadbent has explained this by the hypothesis that such functions are represented in both sides of the brain, and that in destruction of one cortical center the movements are controlled by the remaining center. This explanation has been generally accepted.

It is a fact, however, that the function of the muscles on the side opposite the lesion are always somewhat impaired, as, for instance, in looking upward, the brow on the affected side is not wrinkled so much, nor can a hemiplegic shut the upper eyelid alone on the affected side. It is to be expected, therefore, that the function of the respiratory muscles on the paralyzed side should be diminished.

The explanation of loss of inhibitory control is a purely theoretical one. We do not really know what loss of inhibition means. It is much more logical to believe that in a lesion, such as would result in hemiplegia, there would be loss of function of the opposite side, but that in bilateral functions, instead of a paralysis, there would be only a paresis of function, consequent to the still remaining cortical control of the sound side.

\section{EDFMA.}

A slight amount of edema in hemiplegia is not a rare condition. Mills, ${ }^{8}$ in a study of sixty cases, found edema in seven. In only two cases did I find a great deal of edema. Allen ${ }^{9}$ recently reported a case of extensive edema of the paralyzed side and was only able to collect three similar cases in the literature, those of Hare, ${ }^{10}$ Preobrajensky $^{11}$ and Gilbert and Garnier. ${ }^{12}$ In Hare's ${ }^{10}$ case the edema was limited to the upper extremity and was sharply defined, there being a line of demarcation. Preobrajensky's case was complicated by an aneurism of the aorta and thrombosis of the vessels, while in Gil-

8. Mils: The Nerrnus System and Its Diseases, p. 583.

9. Allen: Jomr. of Nerv, and Ment. Dis. 471 , 1890

10. Hare: Jour. of Nerv. and Ment. Dis.. p. 471 , 1899

11. Pleobrajensky: Ref. in Revue Neurolog., p. 73, 1897.

12. Gilbert and Garnier: Comptus rend. de la Soc. de Biol., 1897. bert and Garnier's ${ }^{12}$ case the edema was limited to a "succulent" hand.

The following history of a patient with intense edema of the paralyzed side is, therefore, of interest:

Patient.-S. B., aged 52. The family history is unimportant. Had syphilis twenty years before his stroke.

History of Attack.-Three years ago, without any symp toms of illness, he suddenly had an apoplectic attack which rendered him unconscious. Since that time he has had a left hemiplegia. Directly after his attack the whole paralyzed side became swollen, this being marked on the side of the face and chest, the swelling fading away as the median line was approached. The upper extremity was more swollen than the lower. The skin looked shiny and tense and there was no pitting to pressure. At the same time the joints of the af feeted side, especially the wrist and elbow joints, became much swollen and exceedingly tender to the slightest pressure. This edema gradually disappeared, leaving, however, a swelling of the elbow and wrist joints.

Subsequent History.-Examination three years after shows a left hemiplegia, with hardly any edema; the joints men. tioned, however, are still a little swollen. Examination of the urine shows albumin, but no casts.

'Two other cases were observed where the edema was confined to the paralyzed hand, giving it the appearance of a "succulent hand," similar to the case reported by Gilbert and Garnier.

No definite explanation has been given for this phenomenon. Vasomotor disturbance probably plays an important rôle, but it does not explain- why in some cases we do have edema, no matter how slight, and not in others. It is probable, as has been pointed out, that any tendency to edema will be increased by an accompanying nephritis. This has recently been called attention to by Spiller. ${ }^{13}$

\section{VASOMOTOR DISTURBANCES.}

Vasomotor disturbances are very common in hemiplegia. The patient usually complains of a feeling of coldness in the paralyzed limbs, and very rarely of a feeling of warmth. It is not uncommon to see a blue condition of the paralyzed extremities brought on by the lessened circulation. Such phenomena, however, as a hemi-skin eruption and sweating are rare. $\mathrm{A}$ patient who had a hemiplegia of some years' duration called my attention to the fact that he did not perspire on the paralyzed side and, more curiously still, that the affected side of the face and arm did not tan in the sun so much as the healthy side. Another patient had an eczematous skin eruption which was limited to the paralyzed side.

\section{POSTHEMTPLEGIC CHOREA.}

The occurrence of various disorders of movement after an apoplectic attack are rare. Von Monakow ${ }^{\mathbf{1 4}}$ states that in twelve years he saw only two cases of posthemiplegic chorea. Spiller ${ }^{\mathbf{1 5}}$ states that he never saw a true instance of posthemiplegic chorea in an adult, and it has secmed to him that the term posthemiplegic chorea is a bad one, for the movements are not choreiform in character. Gowers ${ }^{\circ}$ also calls attention to this, and does not use the term posthemiplegic chorea, but speaks of the various disorders of movement following hemiplegia. Marie also has recently spoken of the infrequency of posthemiplegic chorea.

A number of explanations have been offered for these phenomena. Charcot ${ }^{16}$ was the first to call attention to

13. Spiller: Prog Med, p 201 1900.

14. Von Monakow: Gehirnpathologie, 1897

15. Spiller: Amer. Med. Assn., 1904. Proceedings Section of Neurology.

16. Charcot: Qnoted by Bonhoeffer, Monatsch. f. Psych. und Neurologie, vol. 1, No. 1. 
this symptom and thought that there was in the intermal capsule in the region of the carrefour sensitif a certain tract, a lesion of which would cause choreic movements. Kahler and Pick ${ }^{17}$ thought that an irritation of the pyramidal tracts anywhere would explain the condition. Gowers $^{6}$ is of the opinion that these symptoms are caused by a lesion of the optic thalamus. Bonhoeffer has, perhaps, given us the best explanation. He believes that a lesion involving the anterior cerebellar peduncle of its continuation into the subcortical ganglia causes disorders of movement. Since Bonhoeffer's ${ }^{18}$ paper other cases have been reported which support this observation.

The following case is of much interest in this connection:

Patient.-J. E., aged 63.

History of Attack.-In September, 1899, the patient had a slight stroke which affected his left side. He improved somewhat, but had a second attack two months afterward. It was not until two months after the second stroke that he developed an irregular movement of his left arm. His condition at present is practically the same, except that the irregular movements have become worse and have involved all of the limbs.

Subsequent History.-The last examination of the patient by Dr. Spiller is as follows: Power in the left upper and lower limbs is diminished, and these limbs are distinctly weaker than those of the right side. All the reflexes in the left side are increased, and Babinski's sign is present. The reflexes on the right side are normal. Sensation for touch and pain is diminished over the left upper and lower extremities. The patient has no knowledge where his left upper $\operatorname{limb}$ is, and, to find his left hand, he has to put first his right hand on the left shoulder. The sense of position is also lost in the toes of the left foot. He does not recognize a pencil, a key and a watch in his left hand, calling these objects a crucifix, but at other times he recognizes objects properly. There is marked ataxia of his left upper limb. The tremor in his left upper limb varies in intensity from time to time, sometimes it is only a movement from the shoulder, at other times the whole upper limb is involved. The movement is chiefly a lateral one from the shoulder, but there is at times a rotatory, flail-like movement. There is some tremor of the right upper limb at times, but it is much less important than that of the left upper limb. There is occasionally a tremor of both thighs, especially the left, consisting of a flexion and extension of the hip.

We have in this case a left hemiplegia of five years' duration, where, besides the ordinary symptoms, there are hypesthesia for touch and pain, ataxia, loss of the sense of position, asteriognosis, and a violent irregular movement of the affected upper limb, with milder movements of the other limbs. It is impossible to test him for hemianopsia, as he lost the sight of both eyes some years ago. A lesion in the parietal area would explain all of these symptoms, except the irregular movements. These movements probably are not hysterical, for suggestive treatment and static electricity have had no influence on him for the past five years.

A lesion involving the superior cerebellar peduncle and the posterior limb of the internal capsule would easily explain all the symptoms, and would correspond to Bonhoeffer's view. The slight tremor of the opposite side could be explained by a partial involvement of the other superior cerebellar peduncle.

The tremor which is present in this case could hardly be called choreiform in character. This was the only instance in which this symptom was observed in the series studied.

17. Kahler and PIck: Vlerteljahrschrift f. Praktisch, Heilkunde, Prag., 1879.

18. Bonhoeffer: Monatschr. f. Psych. and Neurolog., vol. 1, No. 1.
Dr. A. J. Smith has kindly furnished me with the record of a case of hemiplegia where violent movements occurred preceding the apoplectic attack. In this instance the movements were confined to the left arm and the left leg and the lower part of the face on the left side, the tremor being clonic in character, resembling a Jacksonian convulsion. This lasted for about two hours, after which there was a complete left-side hemiplegia.

Such convulsions, while not uncommon in uremic conditions, are rare in organic hemiplegia. Various disorders of movement are liable to occur preceding an apoplectic attack, but we rarely have the opportunity to observe them.

CEREBRAL MUSCULAR ATROPHY.

A great deal has been written concerning atrophy of the muscles in hemiplegia, and yet the cause of this atrophy still remains in doubt. It has been said that atrophy accompanies every case of hemiplegia, that it is not a complication but a symptom. Lately Marinesco ${ }^{19}$ and Steinert ${ }^{20}$ have confirmed this observation. In my own cases I also found that atrophy was present in every case. The degree of atrophy varies in different cases, sometimes coming on very early after the onset, and again not for some months.

The atrophy probably first manifests itself in the small muscles of the hand and in the muscles of the shoulder, it being, perhaps, more casily seen in the latter situation because of the bulk of the muscles and the bony prominences. It is more marked in those cases in which the paralysis is marked, and, as it has been pointed out by Mills, ${ }^{8}$ it is greater in the distal part of the extremity. The lower limb is never so much affected as the upper limb. In the majority of cases sensory changes were found, this agreeing with other observers. In quite a large number of my cases considerable atrophy was also observed on the so-called sound side.

Charcot $^{21}$ in 1874 recorded his classic case of atrophy in hemiplegia, where microscopically secondary degeneration and atrophy of the cells of the anterior horns of the spinal cord was found. Since then his observation has been confirmed by a number of investigators. This has not been accepted, however, as an explanation for the atrophy, because later methods have failed to show atrophy of the cells of the anterior horn.

Borgherini, ${ }^{22}$ Quincke ${ }^{23}$ and Eisenlohr ${ }^{24}$ believe that the atrophy in hemiplegia is due to an alteration of the trophic centers in the brain, these centers being situated either in the cortex or near the optic thalamus.

Darkschewitsch ${ }^{25}$ and later Gilles de la Tourette ${ }^{26}$ believed that the arthropathies which are so common in hemiplegia were the sole cause of the atrophy.

Steiner ${ }^{27}$ thinks that there must be a congenital predisposition to disease in the cells of the anterior horn, for, he says, there is not atrophy nor alterations in the cells of the anterior horn in every case.

Roth and Muratow ${ }^{28}$ believed that a destruction of the vasomotor tracts caused a disturbance of the blood supply to the muscles, thereby interfering with the

19. Marinesco: Semaine Med., Nov. 23, 1898.

20. Steinert: Deutsch. Zeitschr. f. Nervenh., vol. xxiv, 1903.

21. Charcot: Lec. sur les localisations, Oeuvres compl, vol. Iv.

22. Borgherini: Arch. f. klln. Med., vol. lxv, Nos. 5, 6.

23. Quincke: Arch f. klin. Med., vol. xili, p. 492, 1888.

24. Eisenlohr: Neurolog. Centralbl., 1891 .

24. Eisenlohr : Neurolog. Centralbl., 1891.

26. Gilles de la Tourette: Soc. Med. des Hôpitaux, 9, 4, 1897 ; ref. in Semaine Med., 1897, p. 130.

27. Stelner: Deutsch. Zeltschr. 1. Nervenh., vol. ilf, p. 280.

28. Roth and Muratow: Ref. Archiv. de Nenrologle, p. 300, 1891. 
mutrition and causing atrophy. Lately Luzzatto ${ }^{29}$ has supported this view. Marinesco ${ }^{19}$ thinks that normally the pyramidal tracts carry vasomotor impulses which act on the medullary center of the sympathetic system, and that in a hemiplegia these influences are destroyed, and there is a consequent stasis in the blood vessels, a lessened blood supply and atrophy. Oppenheim ${ }^{30}$ and Von Monakow ${ }^{\mathbf{1 4}}$ also support the vasomotor theory.

Steinert ${ }^{27}$ has very recently supported the theory that atrophy in hemiplegia is the result of the trophic influence of one neuron upon another. He believes that the cortico-spinal motor tract or the upper neuron has a direct influence on the lower neuron, and that in a lesion of the former there should be alterations in the latter.

ARTHROPATHIES.

Recently Marie ${ }^{2}$ defined for us what is to be understood as an arthropathy in hemiplegia. It is, according to him, a disturbance of function in the articulations of the paralyzed side, especially of the shoulder; the voluntary movements are very limited, and pain is caused by the attempt to move the limb passively, but there is neither reddening nor tumefaction except, perhaps, in some tendinous sheaths.

That this condition was not quite understood by the older writers is evident by the description of Charcot, ${ }^{31}$ according to whom the arthropathies of hemiplegia are a late manifestation and are characterized by pain of greater or less intensity closely resembling the painful crises of rheumatism, and are accompanied by reddening of the skin, tumefaction of the articulations, with an increase in the synovial fluid.

Weir Mitchell ${ }^{1}$ described a similar condition, but in his case the painful swelling of the joint came on four days after the onset of hemiplegia. The same author also described a painful condition of the joints preceding the attack of apoplexy.

Marie does not consider these as pure nervous arthropathies, but as arthrites of probably infectious origin, and he further justly remarks that there is no resemblance between these neurospinal arthropathies and the simple arthropathies so common in hemiplegia, and that at the autopsy one finds in the latter only a slight degree of synovitis without lesion of the cartilages, but marked participation of the synovial tendon sheaths.

I have found in only one case the arthropathy Charcot speaks of, viz.: in the patient previously referred to, when discussing edema. This man, a few days after his seizure, had great edema on the paralyzed side with marked swelling of the elbow and wrist joints and a lesser involvement of the shoulder joints. These joints were very painful and tender to pressure, the skin was reddened and there was tumefaction of the articulations. The joints of the lower extremity were not involved. 'The pain persisted about one year, and at present, three years after the attack, there is still a swelling of the elbow and wrist joints, it being possible to move the articulations in any direction.

I have observed still another patient, in whom it was possible to move the wrist and all the finger joints frecly in any direction. This woman gave no history of pain nor tenderness in the affected parts, but said the flexibility came on gradually. In two more instances I have observed a similar condition in the articulations of the fingers only.

29. Luzzatto: Deutsch. Zeltschr. f. Nervenh., vol. xxili, 1903.

30. Oppenheim : Lehrbuch der Nervenkrankhelten, 3d ed., p. 612 1902 .

31. Charcot: Quoted by Marle.
It may be that the painful joints spoken of by Charcot and also present in one of my cases are caused by an infection. It has seemed to me, as Gowers' has already pointed out, that there is.an analogy between this condition and the similar inflammation which is secondary to acute myelitis.

'There is also a similarity between the painless arthritic conditions present in three of my cases and the arthropathies found in chronic spinal diseases.

In the majority of hemiplegias we find the condition described by Marie. The shoulder joint is usually most affected, but in cases where the contractures are marked all of the joints may be involved. Many theories have been advanced to explain the cause of these arthropathies. Charcot and Joffroy believed that they were due to a secondary alteration in the cells of the anterior horns; Hitzig, ${ }^{32}$ to the pulling on the articulations and the tendons by the weight of the paralyzed extremities; Gilles de la Tourette, ${ }^{33}$ to the forced immobility; Marinesco, ${ }^{34}$ to vasomotor disturbances, and by others to rheumatism.

Most probably the cause can be ascribed to the forced immobility plus the pulling on the articulations and tendons by the weight of the paralyzed member. Alterations in the cells of the anterior horns are not common in hemiplegia. I have examined the cells of the anterior horns in eight cases of hemiplegia. In most of these there were marked contractures and arthropathies, without finding any pathologic changes. Spiller ${ }^{35}$ reported a very interesting case of unilateral internal hydrocephalus, where the contractures were very marked, but the cells of the anterior horns of the spinal cord were perfectly normal. Vasomotor disturbances probably play no important rôle in these arthropathies and there is no reason to expect a greater tendency to rheumatic conditions in hemiplegia than in other organic nervous diseases.

This paper will be followed by a pathologic study of hemiplegia.

I am indebted to Drs. Wm. G. Spiller and Chas. S. Potts for the privilege of studying their cases and to Dr. G. Walter, the resident physician, for her assistance.

\section{DISCUSSION.}

DR. Gux Hinsdale, Hot Springs, Va., stated that some cases of hemiplegia which he has seen have been accompanied by the rather curious feature of yawning. At the same time there is a decided tendency to move the paralyzed arm and the paralyzed leg. He has never been able to understand why the process of yawning should start motion in the paralyzed limb, but supposes that it is reflex, though the movement is not a sudden, quick movement, as seen in the knee jerk, but is a much more deliberate one, such as putting the hand up to the head and down again.

Dr. Hugh T. Patrick, Chicago, asked whether the pre-apoplectic pain in the paralyzed parts occurred previous to throm. botic or hemorrhagic apoplexy. If that pain precedes the development of the apoplexy from the hemorrhage, then he does not understand it all. If it precedes the thrombotic variety, then it seems to him that it is quite naturally in line with other symptoms. Dr. Patrick said that, according to Hughlings Jackson, in using the extremities on one side the action of the trunk muscles is more especially on the opposite side. For instance, using the muscles of the right arm naturally produces as a balancing factor a contraction of the trunk muscles on the other side. In carrying a pail of water or in lifting, the resistance must be on the side of the trunk opposite

32. Hitzig: Quoted by Marle.

33. Gllles de la Tourette: Nouv. Iconoge., p. 287, 1897

34. Marinesco: Revue Neurolog., No. 14, 1894 .

35. Spiller: Am. Jour. Med Sci., July, 1902 
to the extremity used. Consequently the muscles of the trunk are involved with the muscles of the extremity on the opposite side. Dr. Patrick asked whether in cases where the pains and tenderness were greater above or below, showed any variation in regard to the degree of the paralysis. Ordinarily the paralysis is greater at the distal end of the extremity, but there are eases in which the paralysis is greater at the shoulder than at the fingers.

Dr. Theodore Diller, Pittsburg, Pa., declared that this study offers another evidence of a fact that is sometimes lost sight of, viz., the very intimate association between sensory and motor functions. He is not sure but that if other so-called pure motor diseases were to be investigated in the same fashion there would be a greater amount of evidence than is now possessed as to the existence of sensory phenomena. For instance, in paralysis agitans there are sensory phenomena and in the muscular dystrophies and atrophies they are sometimes present. Landry's paralysis is spoken of as if it were a pure motor disease; and yet the studies of recent cases (within the last five years) have shown that sensory phenomena nearly always precede or accompany the motor manifestations. Dr. Weisenburg called attention to this fact in a paper published two or three years ago. He went over the published cases very carefully, and found that sensory phenomena were nearly always pres. ent. He doubts whether any of the so-called motor diseases are entirely free from sensory signs or symptoms.

Dr. David I. Wolfstein, Cincinnati, stated his experience with the Babinski sign, namely, the extreme rapidity with which it comes on, and its usefulness in enabling the physician to make a positive diagnosis when coma is present, or where paralysis has occurred. In a case which occurred at 5:30 p. m., and which he saw at $6: 30$ p. m., the Babinski sign was marked. In another case which occurred at $9: 30$ and which he saw at $10: 15$, the Babinski sign was present, and in another case, in which he was in doubt, the diagnosis was confirmed by the presence of the Babinski sign.

Dr. F. F. Coulter, Omaha, Neb., stated that he saw a case of undoubted fracture of the base of the skull very soon after the accident occurred. There was complete coma and hemorrhage from both ears; the patient died, but no post. mortem was allowed, and it was difficult to determine the exact location of the lesion. The Babinski sign was present on both sides within three hours from the time of the accident.

Dr. Frank P. Norbury, Jacksonville, Ill., stated that a physician, who was associated with him for a number of years in hospital work, had hemiplegia about four years ago and died in apoplectic coma. His father died a victim of hemiplegia, as did also his grandfather, which made three cases in direct succession occurring about the same age. This patient lived about four years after the onset of the hemiplegia before he died. He also presented the phenomena of which Dr. Diller has spoken, edema on the right side.

Dr. Albert E. Sterne, Indianapolis, inquired whether Dr. Weisenburg had made any observations on the temperature of the body one either side, and whether there was any perceptible difference in temperature between the two sides of the body. It is certain that in cases observed shortly after the apoplectic attack the temperature on the paralyzed side rises, frequently showing a difference of a full degree.

Dr. Artirur Conklin Brush, Brooklyn, N. Y., thinks that a good deal of importance should be given to these feelings of weakness and numbness, especially in women over 45, as he has learned from experience that they often precede an attack of cerebral thrombosis. He has never noticed them before a cerebral hemorrhage; but in these cases these premonitory symptoms are often replaced by pain.

Dr. H. G. Brainerd, Los Angeles, CaI., stated that some years ago he had an opportunity of holding postmortems on two cases of hemiplegia which were accompanied by great hemiplegie pains. One was the case of a young woman who had hemiplegia occurring during her menstrual period. There we no cardiac lesions found, either during life or after death, and he concluded that the source of the clot might have been from the endometrium. She had a left-sided paralysis with intense pain in the arm and some in the leg. The lesion was found in the internal capsule posteriorly. The other case was that of a woman, aged about 60 , who had a cerebral hemorrhage into the disturbed area about the same part of the capsule, most marked posteriorly. In other words, there was an irritation of the fibers between the cortex and the periphery eausing "referred pains." Dr. Brainerd remembered being called one morning to see a man who had a slight seizure: what little aphasia there was soon passed off. The patient said: "I shall go in the next suc ceeding one; my father died from apoplexy; his father died from apoplexy, and his father died from apoplexy." A few weeks later his prediction came true, making four successive generations in which death from apoplexy occurred.

Di. 'T. H. WeIsenburg, in reply to a question, stated that he did not observe the yawning spoken of and that most of the cases were hemorrhagic in character. In the case of bone pain, where the pain was more marked in the upper arm than in the hand, the degree of paralysis was greater in the hand. Out of 109 cases studied, only 30 showed sensory disturbances. He has also observed the Babinski sign within $2:$ hours after the onset of the hemiplegia and in a case of uremic hemiplegia within 12 hours. In 3 out of the 149 clinical cases studied, the Babinski sign was not obtained; this is not remarkable, however, for Babinski himself states that this refiex may not be present in every organic case In two cases, with autopsy, where the hemiplegia was caused by lesions of the pyramidal fibers in the pons. The Babinski sign was not obtained. He did not make any study of the difference of the temperature on the paralyzed and the sound sides, but Dr. Mills in his book gives a very careful study of this phenomenon in 60 cases. He found the temperature to be diminished in almost every case on the paralyzed side.

\section{A CASE OF LOCOMOTOR ATAXIA WITH A TREMOR RESEMBLING THAT OF PARALYSIS AGITANS.* JOHN H. W. RHEIN, M.D. Neurologist of the St. Agnes Hospital. PHILADELPHIA.}

(From the William Pepper Laboratory of Clinical Medicine and the Philadelphia Home for Incurables.)

At a session of the American Medical Association in June, 1902, I reported three cases of involuntary movements in ataxia. Since that time one of these patients has died, and I was fortunate enough to obtain an alltopsy. The case was one in which a tremor of both arms existed from the early stages of the disease. This tremor was like that of paralysis agitans.

Patient.-A man, aged 57; family history good. He himself had always been healthy, having never had any serious illness of any sort, and has always been temperate in alcohol and tobacco.

History. - - In 1883 he contracted syphilis. The first tabetic symptoms consisted of the characteristic pains of ataxia, from which he suffered for nine years before the other symptoms of the disease made their appearance. Then there gradually developed numbness of the hands, unsteadiness in walking, and the tremor in both hands before referred to. The ataxia gradually increased until in February, 1898, it had become so ir. tense that he could not walk at all, even with assistance.

Examination.-When I examined the patient for the first time, in May, 1898, he was greatly emaciated. He was unable to stand, and every effort at voluntary movements of the legs developed intense ataxia. There was also a marked degree of ataxia of both arms. On the side of the sensory symptoms

* Read In the Section on Nervous and Mental Diseases of the American Medical Association, at the Fifty-fifth Annual Session, June, 1904. 